\section{OBSERVATIONS ON \\ THE SUPPOSED FREQUENCY OF ULCERATION OF THE OS AND CERVIX UTERI.}

By TYLER SMITH, M.D.,

LECTURER ON MIDWIFERY IN THE HUNTERIAN SCHOOL OP MEDICINE, ETC.

To the Editor of THE LANCET.

SIR, - But for the somewhat unexpected termination of the discussion at the Royal Medical and Chirurgical Society, on Tuesday evening, I should have said a few words on the subject of Dr. Lee's most invaluable paper, which would have rendered it unnecessary for me to refer to the letter of Dr. Henry Bennet, in The LanceT of May 18th. I now, however, beg to make a brief reply to that communication.

By admitting that in his 222 cases of "ulceration " he has included cases of "mere abrasion" and "excoriation," Dr. Bennet concedes, in fact, all I contended for in my paper read at the Westrininster Medical Society-namely, that the term ulceration had been used in an unwarrantable manner, and that it was this misuse of a word which had in great measure led to the current abuse of specular examinations, and the treatment of the os uteri by the more violent escharotics.

Dr. Bennet justifies his application of the term ulceration "even to a mere abrasion," by a reference to the definitions given by Mr. Samuel Cooper and MM. Petit and Boyer, and terms my opinion on this subject "a frivolous negation of the term ulceration to abrasions and ulcerations." But no verbal definition will persuade the profession that "ulceration" and "abrasion" are identical. I am sure I might find plenty of definitions of abrasion which would not, with the utmost stretching, include ulceration.

If we accept Dr. Bennet's views, we shall have to treat the loss of cuticle from blistering, the excoriation of the nares and lips in catarrh, the abrasion of the anus in children, \&c., as ulcerations; which would be simply absurd.

Dr. Bennet censures me for expecting, upon the os uteri, an uleer with defined edges, because of "the tenuity of the mucous membrane lining the cervix and its cavity." To this I would observe, that if the deranged mucous membrane be so thin as not to admit of serious ulceration, heroic treatment cannot be necessary for its cure. Moreover, ulceration affecting a mucous membrane, if it were a true ulceration, need no be confined to the mucous tissue, but would extend to the sub. mucous structures. It does so readily enough in the intestines, and in other mucous surfaces.

Dr. Bennet also affects to think I demand evidence of such a character as is presented by a "chronic cutaneous ulcer;" but I do nothing of the kind; I only demand the same signs as those which are seen in other mucous membranes. The fact, allowed by Dr. Bennet, that in the appearances he has described, and upon which his work is founded, "the surface is never excavated," is itself a strong presumptive proof that they are not genuine ulcerations. In what other tissue of the body do we find ulceration, the rule of which is, that there is never excavation, nor loss of substance? But true ulceration of a non-malignant kind does sometimes, though rarely, attack the os uteri. By this real ulceration we may test the "granular os uteri," and show that it is not really ulcerated. Within the last few days I have been consulted by a patient suffering from prolapsus uteri, with an ulcer larger than a shilling, upon the os uteri. It was an unmistakable ulceration, with a smooth, secreting surface, having distinct and elevated edges, between the ulcerated surface and the non-ulcerated mucous membrane. Such appearances are common enough in procidentia.

I have pertinaciously kept to this point of ulceration or no ulceration in leucorrhoea, because $I$ feel that here the question now engrossing professional attention so largely, really centres. If we are, in the 222 cases detailed by Dr. Bennet at the end of his work on Uterine Inflammation, to read frequently "abrasion" or "excoriation" for the formidable word " ulceration," I susnect we shall soon have a right to use milder remedial means than the peracid-nitrate of mercury, the potassa fusa, the nitric acid, \&c., and, by consequence, to diminish the frequency of specular examinations. The removal of one error generally brings down others in its train.

Dr. Bennet says that $I$ and others are "vainly endeavouring to arrest the strong current of professional feeling towards a correct and sound uterine pathology." The extraordinary -manifestation of feeling at the Medico-Chirurgical Society shows that here Dr. Bennet is in error; that the current is sot in the direction he fondly imagined. During the present month, I have had occasion to visit Paris, and I was assured that the conviction, that great error or exaggeration existed respecting uterine disease and its treatment was becoming very prevalent among the profession in that city also.

But there are certain moral considerations respecting the use of the speculum intimately mixed up with this question of ulceration, and upon which I should wish to say a few words. These remarks do not in any way relate to Dr. Henry Bennet. The author of a well-known work on utcrine disease avows that he examined with the speculum 2000 women! who attended at a public charity, including cases of " retention or suppression of the menses," "hysteria, chlorosis, and similar affections." (!) Among these patients were also, "a number of young unmarried females." The writer avows that he "made it a point, whenever practicable," to examine the uterus with the speculum. He considered that in this he was only doing duty " as the recipient of an important public trust." (!) Now, I do not hesitate to say, that these 2000 examinations, made in a spirit of experiment, and not from the conviction of their necessity in each particular case, were 2000 immoralities altogether unjustifiable. No man has the right to go, speculum in hand, amongst the generative organs of living women, just as he would go amongst the dead specimensin a pathological museum. The principle should be, not to EMPLOX the speculum, but to avoid its use " whenever practicable." The endeavour of the true physician must ever be, not to extend its employment as much as possible, but to limit its nse to all but imperative cases. In these remarks I have no wish to be thought to run down the use of the speculum, which is, in some cases, most necessary and important, and could not be compensated for in any other manner. I should desire to defend the use of the instrument, and I firmly believe that if the present rage for employing it were to go on unchecked, the time would arrive when hardly any practitioner of character would feel comfortable in using it at all. I cannot coincide with the opinion that it is no more indelicate, and no greater exposure, to look into the vagina than into the throat! Such things could only be said in perfect forgetfulness of the natural modesty of woman.

In conclusion, I may observe that I have been kindly "blushed for" because I asserted in my paper that women were so alarmed by the reports of the prevalence of uterine disease as frequently to submit to examinations when such proceedings were unnecessary. It seems to me that both the blushes and the blame belong to those who have produced such a feeling as that which I have hinted at, in the female mind. I am, Sir, your obedient servant,

Bolton-street, Piccadilly, May, 1850. W. Truer Smith.

\section{ON THE PRACTICE OF HOMCEOPATHY.}

$$
\text { Honesté stultum. }
$$

\section{BY ROBERT DICK, M.D.}

THE safety of Homœopathy lies in its mystery; otherwise it would be easy to demonstrate that its doctrine of similia similia curant is the most impudent mis-statement ever made. The homœopathist resembles a juggler, who (in his infinitesimal doses) always keeps out of sight, as it were, and then tells us that the fire, air, and water, which, in our hands, have their known ordinary effects, produce, in his, results quite different, because manipulated, in a certain way, into infinitesimal dilution! Were there the ordinary measure of magnitude for the homcopathic dose, we could soon bring the theory to a conclusive test. We would say to the practitioner of this school-" If one globule from this bottle produces symptoms analogous to inflammation, then surely five, ten, or twenty, or 100 globules will produce these symptoms in an aggravated degree. Give me, therefore, 100 globules, or, if thev are bond fde infinitesimai, give me 1000 , or 10,000 I am ready to stand the risk of the inflarnmation." This, I have been informed, was the proposal which the late Mr, Liston made. He offered to swallow, at one dose, the whole pocket dispensary of a homœopathist; but he was told, $I$ believe, that the experiment, even if made, would not be conclusive, because, by medicines taken in large or allopathic doses, the peculiar homoopathic effects of small doses are not developed, (an apparent very obvious truism;) and secondly, because it is necessary that a person should be suffering from a disease similar to that which the medicine causes before the peculiar effeots of that medicine can be illustrated. What a jumble this of ineonsequence, contradiction, and assumption. By what means does the homoopathist obtain his knowledge 
of the effects of medicines but by experiments on persons in health; else, how would he know that the effects of any particular substance are similar to disease; since the experiment, if made during disease, would leave it vague whether the morbid effects were due to the drug or the disease. Then, unless the modes of computation or measurement in regard to homoopathic medicines are opposed to all others, and are of a nature mysterious and miraculous, it follows, that if one, two, or three globules of a given substance cause symptoms resembling inflammation, fifty or 100 globules of the same substance will excite these symptoms in a higher degree. Then give us that dose. The writer offers, either in health or when he chances to suffer from sickness, or in any other circumstances, to take a thousand doses at once of any substance whatever of the ordinary infinitesimal dilutions. He stipulates only to have two allopathic practitioners to superintend the effect, in order that they may prove, as he doubts not they will easily do, that any phenomena (favourable or the reverse) which may follow, are explicable on grounds altogether distinct from the infinitesimal dose; unless, indeed, this is taken in so large a quantity as to act on ordinary allopathic principles; which, however, of medicines infinitesimally diluted, many thousand doses ought not to do. We repeat our offer. We invite homeopathists, by any infinitesimal use of their medicines that pleases them, to get up in us a pleurisy, pneumonia, peritonitis, or fever. For the interests of art and knowledge, and for the sake of testing the efficacy of infinitesimal doses, we are willing to incur the risk. But candour compels us, at the same time, to avow that we consider we make the offer with the most perfect safety !

Here, then, is a remarkable difference between the two systems. The allopathist at will, and irrespective of the voli. tion of the patient, can by his doses, purge, or cause to vomit, or to perspire, or to void urine in large quantities-can, in short, act, at his pleasure, on important organs and functionsthe bowels, stomach, skin, kidney, \&c. We can stimulate by quinine, or depress by antimony. But the writer, and those who think with him, absolutely defy homoopathists, when using only bona fide infinitesimal doses, to produce the smallest effect on them, either in health or disease. In other words, we assert that the action of infinitesimal doses is purely imaginary, and is all explicable on the ground of influencing the imagination of persons, who are predisposed by faith in the system, and whose cases do not require more active treatment. Can we possibly offer a fairer issue than this?

Yet absurd as the infinitesimal doctrine is, to it (we verily believe) homœopathy chiefly owes what popularity it enjoys. Did this system not differ from the Hippocratic in the marvellous minuteness of its doses, but merely in the principle on which medicines are administered, it would probably never have obtained any or much attention; for the curiosity of the public, more especially the morbid curiosity of hypochondriac men and nervous women, would not have been stimulated. Whether the black draught he was about to swallow was to act on homcopathic or allopathic principles, a patient would not have cared one straw about; but when he is not only spared the black draught, but required merely to swallow a powder smaller than the smallest pinch of snuff, or to take a teaspoonful of limpid, tasteless, and colourless water, - when, moreover, he is told that in these he imbibes only a decillionth part of the active agent, his palate and his faculty of wonder are conjointly interested in the miraculous circumstance! I need not add what every man lknows, that, besides men like Lords Fssex and Robert Grosvenor, there are multitudes of women (more excusable, indeed) who prefer whatever taxes their faith, stimulates their imagination, excites, but never satisfies their curiosity, and exceeds their comprehension, to aught their minds could fathom!

We onght not, however, to quit the subject of infinitesimal doses without urging a suggestion on all our allopathic brethren. It is known that two or three years ago, one of the most notorious of the metropolitan homoopathic practitioners was detected in administering to a delicate female patient, as infinitesimal medicine, a dose of the chloride of mercury, such as few allopathists would in the same circumstances order. We apprehend that this mendacious method is far from rare. It were easy for an homœopathist to administer an allopathic dose of arsenic, corrosive sublimate, strychnine, aconitine, morphine, and other powerful medicines, as an infinitesmal one. And this, as we have just said, we doubt not is often done. We therefore recommend our brother practitioners to embrace any opportunities, consistent with gentlemanly dealing, of abtaining specimens of homœopathic medicines, from friends or patients who have been under that treatment, and to analyze the same. We suspect that some curious disclosures will be the result.

Our total scepticism, as to any effect whatever from infinitesimal doses, necessarily obliges us to the belief, that in every case in which any benefit does result from a medicine ostensibly infinitesimal, a deception is practised; the dose not being, in diminutiveness, what it is professed to be. And hence will arise a difficulty to allopathists in practically confuting the system of their opponents, by pointing to its inefficiency; since the treatment of the latter will be, and we doult not in many cases now is, allopathic, under the colours of homceopathy!

We do not hesitate to avow, that we consider as the most noble as well as the most perfect and safe of all cures, to be that which is effected by natural means only, by an enlightened and masterly application of physiology; and we even think it might be, with less sophistry and paradox than is employed on many occasions, maintained, that the means just referred to are the only ones for which we have clear, express, direct, and indisputable warrant. The line of argument, however, necessary to establish even the probability of this, would be much too transcendental for the pages of a practical medical journal. Besides, a contrary view might be also plausibly maintained, and on another tack of reasoning from the transcendental one just adverted to, the use of medicine might be shown to be the result of a sort of secondary instinct. These are grand and exciting inquiries, for the management of which the time we live in is not prepared. With all our vanity and imagined progress we are a gross age. The finest departments of knowledge and social humanity are neither understood nor regarded by us, or are named only to be derided and execrated. But, returning from this digression, and leaving open the questions above referred to, we shall simply remark, that, whether rightly or not, the use of medicine is likely to be long a habit of the race. And of the two medical sects discoursed of in this paper, homœopathists and allopathists, we are well convinced that the latter will survive, will regain all the advan tages it may lose, and will number the apparently most brilliant cures. The tables will be again turned.

In order to prove this, let us for a moment imagine that homœopathy, with its inert and slow treatment, was universally established, and that the very name and memory of allopathy had died out of the world. Let us next imagine that amid this state of things an allopathist appeared, armed with opium, mercury, antimony, nitrate of potass, \&c., and administering them in allopathic doses; giving this man, who had been for weeks sleepless, a night of profound repose, by a single pill (opium); sending, by the use of a single small powder (calomel), that other man, who had been all his life constipated, to his water-closet, in a state of unprecedented alvine urgency and excitement; by a powder, equally minute, (tartrate of antimony) producing a vomitive cataract from the stomach of that clild, who had over-eaten itself with acerb plums, and ached in its small abdomen; cansing a fourth person (a dysuric patient), by a powder not large (nitrate of potass), to charge his chamber utensil with a more brimming supply than the joyful man had ever impinged into it before! Why, the whole world would go mad about this allopathist! He would be called a miracle-worker. Man and woman would flock all wildly after him. The tail of his coat, if coats should then be worn, would be kissed by beseeching. and by thankful lips. Homœopathy would be forgotten, or laughed at as the wretched dawding of old women; and nothing would be talked or thought of but the apparition of this wonderful new medical demi-god!

Norfolk Terrace, Westbourne Grove, West.

\section{ON A NEW AND LAMENTABLE FORM OF HYSTERIA.}

By MARSHALL HALL, M.D., F.R.S., \&c.

I HAVE no doubt that I was one of a considerable number who, at the last meeting of the Royal Medical and Chirurgical Society, (a meeting which will long be memorable in its annals, ) wished to express their sentiments on the subject of the use of the speculum vaginæ, without having what they deemed the perfect opportunity. I regret that the discussion was not adjourned to another evening.

I think the profession deeply indebted to Dr. Robert tee for bringing this question forward for discussion. It is not one of mere medical or surgical treatment, but of medical and public ethics; and $I$ confess myself astonished at the light 